\title{
To Assess the Neuropsychological Deficits and to Study the Efficacy of Therapy based on Optimism-Attitude Model (OAM) for Substance - Dependence Patients
}

\section{Banerjee P* and Bedi S \\ Amity University, Gurgaon, India}

*Corresponding author: Padmakali Banerjee, Pro Vice Chancellor \& Dean Academics Director Amity Business School, Amity University, Gurgaon, India, Tel: 9871054449; E-mail: padmakali@ggn.amity.edu

\section{Research Article \\ Volume 3 Issue 1}

Received Date: December 28, 2017

Published Date: February 06, 2018

\section{Abstract}

Background: Substance dependence disorder is an epidemic of global world and results in various kinds of deficits in cognitive, social, personal and economic loss of the person. Person with SUD'S tend to perform poor on various cognitive task and has impaired executive functioning, poor verbal fluency, impaired judgment and poor emotional and social functioning. Various treatment programs have been developed in order for the patients with SUD'S to get benefit from the treatment and improved cognitive and social functioning.

Objectives: This study aim to assess and understand the neurocognitive functioning present in the Substance Dependence patients and to study the efficacy of therapy based on OAM for substance dependence patients.

Methodology: The present study consists of sample of 100 male substance-dependent patients admitted in Psychiatric and De-addiction Centre in Delhi. Participants completed Neuropsychological functioning test and was then directed for therapy involving 14 sessions, each lasting 45 minutes during their stay in hospital. Therapeutic Sessions was focusing on individual level of optimism, desire to change, patient attitude and behavior towards change and to understand their selfefficacy. Patients who were attending therapy sessions were instructed to fill various self-reports measures to understand the impact of therapy before and after the sessions.

Results: The results showed that therapy based on OAM model impact the participants attitude and behavior towards positive outlook enhancing their level of optimism, improved self-efficacy and desire to change and maintain the changed behavior.

Conclusion: The implications for the practice of therapy based on OAM in the treatment of Substance- dependence is notable and this therapy got future implications in other area of mental health.

Keywords: Substance Dependence (SUD’s); Optimism-Attitude Model (OAM); Neuropsychological deficits; Self-efficacy 


\section{Psychology \& Psychological Research International Journal}

\section{Introduction}

Substance dependence is alarming issue not in India alone, but for the entire world. The use of various substances is evident in histories and across various cultures which varies from country to country. The problem of substance abuse is growing at an explosive rate and in just little over a decade it has spread its malevolent tentacles to almost every part of the globe surmounting almost all barriers of race, caste, creed, religion, sex educational status, economic strata etc.

Dependence on any kind of substance is manifested through a strong desire to use the substance, poor control over the use of substance, withdrawal symptoms when reducing or stopping the use of, having tolerance to the effects of substance and continuing the use of substance despite knowing the serious consequences of the substance (ICD-10). Most of the substances like Cocaine, Heroin, and Nicotine are highly addictive after the first use only and produce various kinds of cognitive and psychological problems. All these illicit drugs produce a decrease capacity to respond to one's surroundings and a loss of personal and social judgment. The substance dependence disorder is associated with various psychological and neuropsychological disorders and impairs individual cognitive, social, occupational and emotional functioning.

Various kinds of Psychotherapeutic treatment approaches are available for Substance Dependence including motivational Enhancement Therapy, Cognitive Behavior Therapy and other types of Behavior therapy. The present study focus on the efficacy of OptimismAttitude Model and on the principals of this model the therapy is given to the patients of SUD'S. The therapy is based on the notion that higher level of optimism improves the person's overall well- being which in turn brings positive behavior change and improves the attitude of the person towards himself and society. Therapeutic treatment of SUD'S states that behavioral change is an important factor in measuring the success in changing one's old behavior pattern of taking substance.

\section{Aim of the Study}

The first aim of the study was to identify the various cognitive deficits present in substance dependence patients. The second aim was to explore the efficacy of Optimism-Attitude (OAM) treatment model for inpatients of substance dependence disorder

\section{Review of Literature}

According to WHO (2010), dependence on substance, over dose of drugs, misuse of the drug are serious health risks associated with substance dependence. Researchers suggested that by the age of 18 years or may be less having reported of substance use in their life. According to UNODC (2015) it is estimated that over 5 percent of those ages 15 to 65 years worldwide used various kinds of drugs. Men are three times more likely than women to use various substances like cannabis, cocaine and amphetamines. Substance dependence disorder is the result of various Bio-Psycho-Social factors which plays an integral role of putting person to initiate the use of substance.

Literature on Family studies suggest that the risk of SUD'S increases to double in offspring of parents with SUD'S. The person is exposed to various kinds of drugs in very early life and therefore find it difficult to escape from such environment. Poor socio-economic condition of the family, homelessness, poor family environment, early drop-out from the school and jobless family environment also plays an important role in contributing the substance use. Childhood emotional and behavioral problems like poor parenting style, death of the parent, divorce of the parent also contribute in the risk of getting into substance $[1,2]$. There are other important factors that contribute to the cause of substance dependence disorder such as children who are impulsive, restless, or vulnerable were more than two times as likely to be indulge in substance dependence. Physical and Sexual Abuse in adolescents also results in indulgence in substance as a form of escape from the environment.

Apart from impaired behavioral functioning, substance dependence has also been linked to affect the cognitive functioning of the individual. Various studies done to understand the deficits in cognitive functioning such as deficits in working memory, poor attention span, impaired verbal fluency, poor comprehension ability and impaired judgment [3-7]. There are various psychosocial treatment available in the literature for the management of substance dependence disorder, the recent advances in the treatment approach is the topic of interest this research. Banerjee (2016) [8] has developed Optimism Attitude Model (OAM), and keeping the principals of this model the Optimism-Attitude Therapy was used as the model of treatment for substance dependence population.

According to Miller (2003) [9], the treatment outcomes indicate that the behavior of the participants changed 


\section{Psychology \& Psychological Research International Journal}

because the root cause of their existing behavior no longer existed. While the outcome of this study strongly suggests that this particular version of Optimism Attitude Therapy may be useful for the treating of substance dependence. Sobell, et al. (1993) [10] stated that the major factor which help in maintaining recoveries during and after the treatment it has been found that adequate Social support is a crucial component for effective treatment program [11].

\section{Methodology}

\section{Sample}

100 Male substance-dependent participants were recruited from a Delhi based hospital with high intensity residential substance abuse and detoxification treatment program. This is a government funded inpatient detoxification and de-addiction Centre (30 days or more) for treatment of persons with substance abuse disorders. The therapists, counselors and intake staff of the hospital were provided with an copy of the inclusion or exclusion criteria of the participants in this study.

\section{Sampling Method}

While selecting the participants for the study, Purposeful method of sampling was used. The participant for the study was selected based on the assumption that they will be able to provide information that is both detailed and generalizable. The participants who meet the inclusion criteria possess rich information and experiences making them information rich cases and helps in better understanding of the problem and planning a treatment management

\section{Inclusion criteria:}

- Males diagnosed with substance -dependence disorder according to ICD-10 criteria of diagnosis.

- Age group between 18-50 years

- No alcohol intake from last 1 year

- All participants had to report using cannabis, cocaine, stimulants, sedatives, opiates, hallucinogens or inhalants on at least a weekly basis prior to coming to treatment

- Participants still experiencing daily craving for substance

\section{Exclusion Criteria:}

- No prior history of severe brain injury, seizure, not prone to fainting, not claustrophobic.

- No prior History of major psychiatric illness, mental retardation

\section{Measures}

Demographics Questionnaire: A demographics questionnaire was designed for this study .The questionnaire was used to gather information about participants: date of recovery, length of abuse, primary substance of use, other substances used, first substance ever used, age of first use, number of times they have been to substance dependence treatment, number of relapses, and what has been the most instrumental in their recovery.

The Life Orientation Test-R (LOT-R): is a 10 item scale which assesses the individual's tendencies to anticipate favorable consequences [12]. The LOT-R items are rated on a five-point scale ( 1 = I agree a lot; 5 = I disagree a lot). Higher total scores refer to greater levels of optimism.

The Cognistat (Indian Adaptation): Cognistat is highly reliable and valid test to measure Cognitions on the Indian Population. Various subtests of COGNISTAT assess major domains of cognitive functioning namely, orientation, attention, language (further divided into spontaneous speech, comprehension, repetition, naming), construction, verbal memory, calculations, and reasoning (further divided into similarities and judgment).

\section{Procedure}

The diagnosis of Substance Dependence for all the 100 clients was made by the psychiatrists of Psychiatric Department of the Hospital and De-Addiction Centre, New Delhi. Once the patient had completed the inpatient detoxification program of 1 week they entered the hospitalization program, and was approached to participate in this study. Informed consent was obtained by the researcher (explaining the study aims, design, and risks/benefits), and signed documents was to be remain in a secured file. During their first two days of the program, consenting patients was given a brief neuropsychological battery-Cognistat. After the completion of testing the participants were included for 14 session's psychotherapy. The sessions were conducted by the researcher who is the professional psychotherapist. The sessions were held 2 days in a week lasting 40-45 minutes each. In the beginning of psychotherapy session the client was given various questionnaires to be filled. The structure of the therapy sessions are given in detail. The case history of all the 90 clients in the intervention groups were taken by the Researcher. The clients' demographic information, personal history, family background and information about the presenting problem were noted down carefully. 


\section{Psychology \& Psychological Research International Journal}

\section{Application of Therapy on the Basis of Optimism Attitude Model (OAM) in the Study}

In the present study, OAM was carried out as a treatment modality for substance dependence patients. On the whole, 14 sessions were conducted. The patients received 2 session of therapy in a week and each session lasted for approximately 40- 45 minutes (Figure1).

Optimism Attitude Model explain how 'Optimism' can enhance the client Positive Emotions, Engagement, Relationship Network, Meaningfulness and Accomplishment thereby building resilience and inviting success in one's life.

In this study various techniques encompassed in therapy for increasing the mental efficiency of the individuals are incorporated. Optimism is the expectation that good things will happen. In addition, more optimistic people tend to hold generally promising expectations for the future. When faced with challenges and adversity, individuals with higher optimism confront it with more positive belief, confidence, and persistence. OAM has benefitted individuals immensely who are suffering from various anxieties, depression, inferiority complex, low self worth, adjustment issues and even substance abuse. When faced with challenging situations like changing the wrong behavior of using substance the individuals who were using OAM therapy could confront it with positive beliefs, confidence and persistence. They remained positive of the situation despite present setbacks and ultimately emerged winners (Table 1).

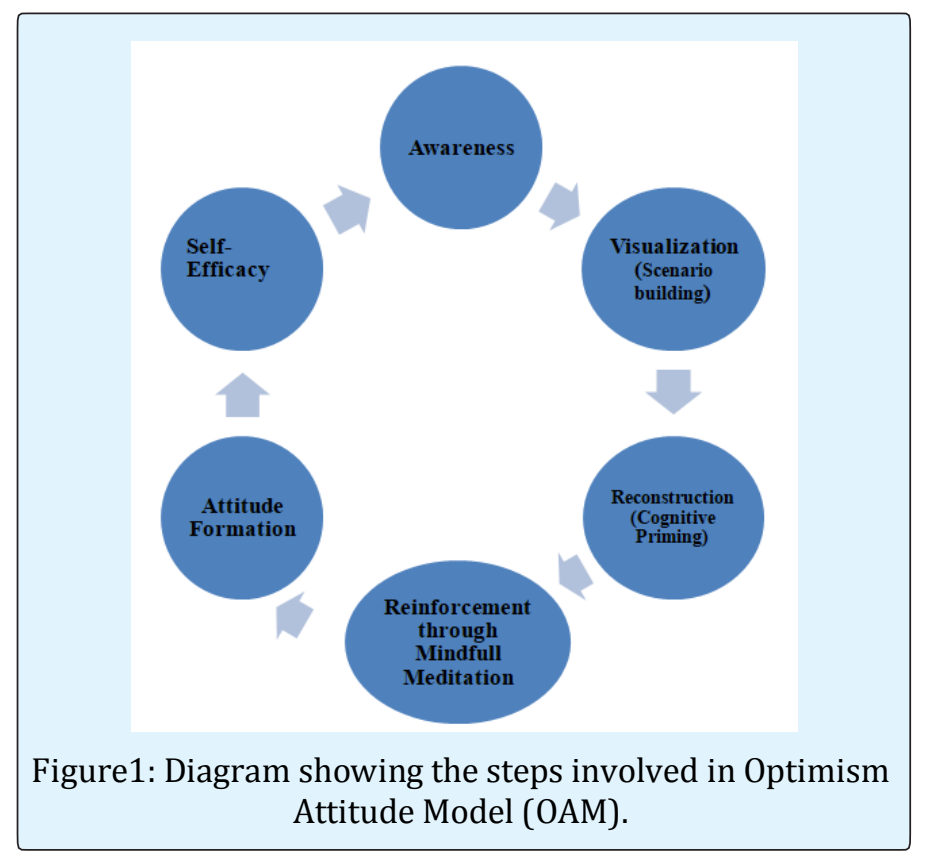

\begin{tabular}{|c|c|}
\hline OAT Steps & Procedure \\
\hline 1.Awareness & \begin{tabular}{|c|} 
Understand the patient's views of \\
use of substance; Develop \\
discrepancy between patient's goals \\
and actual behavior, Ask Pros and \\
Cons and Review Health Risk
\end{tabular} \\
\hline \begin{tabular}{c|} 
2. Completion of \\
Self-Report scale \\
Positive \\
Visualizations \\
Scenario Building
\end{tabular} & $\begin{array}{l}\text { Ask to visualize life when they have } \\
\text { stopped taking substance, prompted } \\
\text { to increase the positive elements } \\
\text { during visualization process. }\end{array}$ \\
\hline 3. Cognitive Priming & \begin{tabular}{|c|} 
Presentation of Optimistic Videos, \\
Real - life successful stories, \\
motivational quotes, visual \\
advertisements that brings out \\
positive message
\end{tabular} \\
\hline $\begin{array}{l}\text { 4.Mindfulness } \\
\text { Meditation }\end{array}$ & $\begin{array}{c}\text { Focusing on the breath in } \\
\text { meditation position, body scanning } \\
\text { in a relax posture Meditation act as } \\
\text { cleanser process; enhance } \\
\text { acceptance of present moment } \\
\text { experience, decision making ability, } \\
\text { unlearning wrong behavior }\end{array}$ \\
\hline 5.Attitude change & \begin{tabular}{|c|} 
Explaining the concept of change as \\
a process rather than single event \\
Expressing optimism and intention \\
about Change
\end{tabular} \\
\hline $\begin{array}{l}\text { 6. Supporting Self- } \\
\text { Efficacy }\end{array}$ & $\begin{array}{l}\text { Support Self-Efficacy and Self- } \\
\text { worth Reminding clients of past } \\
\text { successes in avoiding using } \\
\text { Substance and Positive Future- } \\
\text { Visualization Confidence Building }\end{array}$ \\
\hline
\end{tabular}

Table 1: Structure of Therapy based on Optimism Attitude Model (OAM).

\section{Statistical Analysis}

The data of the study were analyzed using SPSS for Windows (16 ${ }^{\text {th }}$ version). The subtests of COGNISTAT were scored and adjusted according to the descriptive statistical methods. Detailed interviews were taken to examine the effectiveness and impact of an OptimismAttitude Therapy (OAT) of persons suffering from SUDs.

\section{Qualitative Research Design}

For the present study the qualitative research design was implemented to understand the effectiveness of therapy on Substance dependent patients. The Content Analysis method was used as the qualitative research method in this study. The process involves putting order to the data, organizing the data and creating pattern of the 


\section{Psychology \& Psychological Research International Journal}

data, categorizing the data and giving descriptive units to the data. This entire process involves close examination, creative insight and careful attention.

\section{Ethical Considerations}

Ethical issues which were considered in the study are permission to collect data, debriefing, voluntary participation, informed consent, confidentiality and the protection of the right of participants.

\section{Results}

The following section details the results of this research. First, the data collection sample is presented. Second, the therapy findings are presented, including a description of from the perspectives of the participants; the participants experience with therapy an in-depth analytic understanding of Optimism-Attitude Therapy.

\begin{tabular}{|c|c|c|c|c|c|}
\hline & $\mathbf{N}$ & Minimum & Maximum & Mean & S.D \\
\hline Orientation & 100 & 4 & 12 & 7.12 & 1.73 \\
\hline Attention & 100 & 1 & 6 & 3.76 & 1.52 \\
\hline Construction & 100 & 0 & 4 & 2.29 & 0.956 \\
\hline Memory & 100 & 0 & 10 & 6.38 & 1.65 \\
\hline Calculations & 100 & 0 & 3 & 1.25 & 0.743 \\
\hline Comprehension & 100 & 2 & 5 & 3.16 & 0.849 \\
\hline Repetition & 100 & 5 & 11 & 6.78 & 1.6 \\
\hline Naming & 100 & 2 & 7 & 3.23 & 1.34 \\
\hline Similarity & 100 & 2 & 5 & 2.91 & 0.943 \\
\hline Judgment & 100 & 1 & 4 & 1.88 & 0.89 \\
\hline Valid (N) & 100 & & & & \multicolumn{1}{|c|}{} \\
\hline
\end{tabular}

Table 2: The descriptive statistics of the dimensions of Neuropsychological functioning of Substance Dependent patients $(\mathrm{N}=100)$. The table shows the maximum, minimum, mean value and standard deviation of different dimensions of Neuropsychological functioning.

According to the test results the mean score on Orientation domain is $(\mathrm{M}=7.12, \mathrm{SD}=1.73)$, Attention domain is $(\mathrm{M}=3.76, \mathrm{SD}=1.52)$, Construction domain is $(\mathrm{M}=2.29, \mathrm{SD}=.956)$, Memory domain is $(\mathrm{M}=6.38, \mathrm{SD}=1.65)$, Calculation domain is $(\mathrm{M}=1.25, \mathrm{SD}=.743)$, Comprehension domain is $(\mathrm{M}=3.16, \mathrm{SD}=.849)$, Repetition domain $(\mathrm{M}=6.78$, $\mathrm{SD}=1.60)$, Naming domain is $(\mathrm{M}=3.23, \mathrm{SD}=1.34)$, Similarity domain is $(\mathrm{M}=2.91, \mathrm{SD}=.943)$ and on Judgment domain $(\mathrm{M}=1.88, \mathrm{SD}=.890)$.

The Mean score on Calculations and Judgment domain is lower than all other domains of cognitive assessment. This can be suggested that substance-dependent patients found to have working memory weakness and math difficulty- arithmetic, algorithm knowledge and problem solving Also the low mean score on Judgment dimension is may be due to the fact that substance dependent patients are poor on quick decision making and often fails to give close attention to details which makes them incapable to take clear decisions.

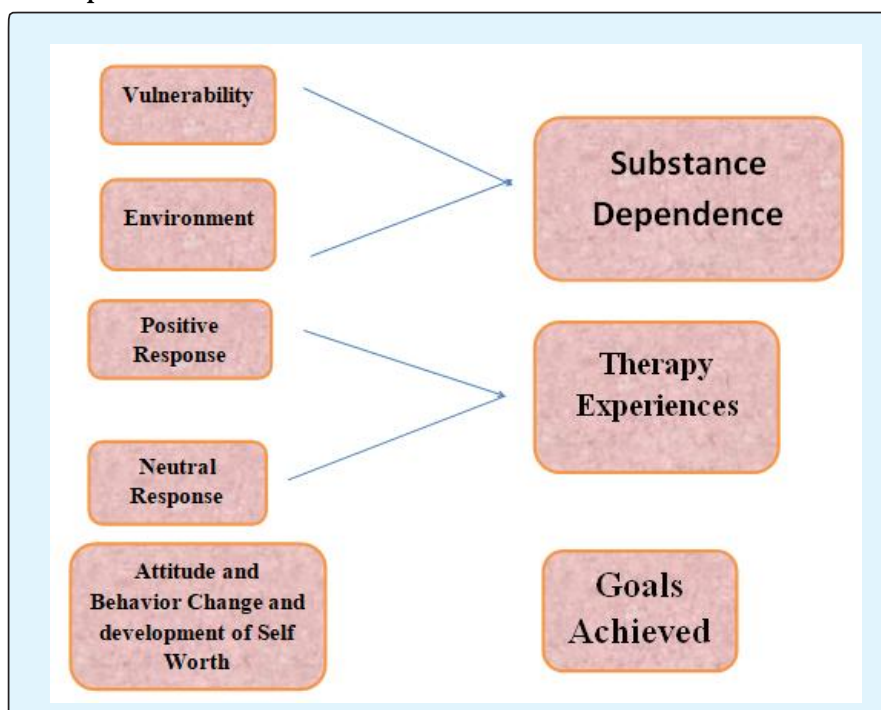

Figure 2: This section presents the results from the interpretive content analysis as super ordinate themes.

Many of the names of the themes are taken from the words the informants used to describe their recovery. Investigator used Med Calc Statistical Software version 16.2.1 for the test that was conducted for Comparison of proportions of percentages; it is a variant of chi Square. At this point of the process, we gathered entire data to form categories which are shown in Figure above:

\begin{tabular}{|c|c|}
\hline \multirow{2}{*}{ Percentage } & Vulnerability $31.5 \%$ \\
\cline { 2 - 2 } & Environment $43.2 \%$ \\
\hline Difference & $11.70 \%$ \\
\hline Chi Squared & 2.61 \\
\hline DF & 1 \\
\hline Significance & $\mathrm{P}=0.1057$ (NS) \\
\hline 95\% CI & $-3.19 \%$ to $26.06 \%$ \\
\hline
\end{tabular}

Table 3: Comparison of percentage proportions of substance dependence in the category of Vulnerability and Environment in Substance Dependence. 


\section{Psychology \& Psychological Research International Journal}

Above Table gives comparison of proportions of percentages of Environment vs Vulnerability in substance dependence and the following were the results:

Percentage of the Vulnerability in Substance Dependence is $31.5 \%$ while in Environment category it is $43.2 \%$, stating there is not a huge difference in the percentages of the two , but still we need some statistical technique to prove our contention, we used Comparison of proportions to compare percentages, if we see the difference we will find it is $11.7 \%$ and chi square comes out to be $2.61, \mathrm{p}=0.1057$, which is non significant, this states that vulnerability and Environment are equally responsible for the state of becoming substance dependent

\begin{tabular}{|c|c|}
\hline \multirow{2}{*}{ Percentage } & Positive Response 51.3\% \\
\cline { 2 - 2 } & Neutral Response 31.5\% \\
\hline Difference & $19.80 \%$ \\
\hline Chi Squared & 7.23 \\
\hline DF & 1 \\
\hline Significance & P=0.0072 (significant) \\
\hline 95\% CI & $4.66 \%$ to $34.02 \%$ \\
\hline
\end{tabular}

Table 4: Comparison of percentage proportions of substance dependence in the category of Substance dependence and Therapy Experience.

Above Table gives comparison of proportions of percentages of positive response vs Neutral Response in Therapy given for substance dependence and the following were the results:

Percentage of the Positive response in therapy is $51.3 \%$ while in Neutral Response category it is $31.5 \%$, stating there is a difference in the percentages of the two, but still we need some statistical technique to prove our contention, we used Comparison of proportions to compare percentages, if we see the difference we will find it is $19.80 \%$ and chi square comes out to be 7.23 , $\mathrm{p}=0.0072$, which is highly significant, this states that there is significant difference between positive response from therapy as compared to neutral response and the positive response of therapy is higher than the neutral response in the therapy given to participants with substance dependence.

\begin{tabular}{|c|c|}
\hline \multirow{2}{*}{ Percentage } & Attitude and Behavior Change 67.5\% \\
\cline { 2 - 2 } & Goals Achieved 72.9\% \\
\hline Difference & $5.40 \%$ \\
\hline Chi Squared & 0.62 \\
\hline DF & 1 \\
\hline Significance & P $<0.42(\mathrm{NS})$ \\
\hline $95 \% \mathrm{CI}$ & $-8.68 \%$ to $19.27 \%$ \\
\hline
\end{tabular}

Table 5: Comparison of percentage proportions of substance dependence in the category of Attitude and Behavior change and Goals Achieved.

Above Table gives comparison of proportions of percentages Attitude and Behavior Change vs Goals Achieved in Therapy given for substance dependence and the following were the results:

Percentage of the Attitude and Behavior change from therapy is $67.5 \%$ while in Attitude Change category it is $72.9 \%$, stating there is not a huge difference in the percentages of the two , but still we need some statistical technique to prove our contention, we used Comparison of proportions to compare percentages, if we see the difference we will find it is $5.40 \%$ and chi square comes out to be $0.62, \mathrm{p}<0.422$, which is non significant, this states that there is no significant difference found in attitude and behavior change and goals achieved in therapy.

\begin{tabular}{|c|c|}
\hline Difference & $36 \%$ \\
\hline Chi Squared & 23.2 \\
\hline DF & 1 \\
\hline Significance & $\mathrm{P}<0.0001$ (Significant) \\
\hline 95\%CI & $20.91 \%$ to $49.36 \%$ \\
\hline
\end{tabular}

Table 6: Comparison of percentage proportions of substance dependence in the category of AttitudeBehavior change and Vulnerability in Substance Dependence.

Above Table gives comparison of proportions of percentages Attitude and Behavior Change from therapy vs Vulnerability in Substance dependence and the following were the results: 


\section{Psychology \& Psychological Research International Journal}

We used Comparison of proportions to compare percentages, if we see the difference we will find it is $36 \%$ stating there is a huge difference between attitude and Behavior change in therapy and Vulnerability factor and chi square comes out to be $23.20, \mathrm{p}<0.0001$, which is highly significant, this states that there is significant difference found in attitude and behavior change and Vulnerability factor in substance dependence.

\begin{tabular}{|c|c|}
\hline Difference & $24.30 \%$ \\
\hline Chi Sqaured & 10.69 \\
\hline DF & 1 \\
\hline Significance & $\mathrm{P}=0.00$ (Significant) \\
\hline 95\%CI & $9.06 \%$ to $38.39 \%$ \\
\hline
\end{tabular}

Table 7: Comparison of percentage proportions of substance dependence in the category of Attitude Behavior change and Environment in Substance Dependence.

Above table gives comparison of proportions of percentages Attitude and Behavior Change from therapy vs Environment factor in Substance dependence and the following were the results we used Comparison of proportions to compare percentages, if we see the difference we will find it is $24.3 \%$ stating there is a huge difference between attitude and Behavior change in therapy and Environment factor and chi square comes out to be $10.69, p=0.00$, which is highly significant, this states that there is significant difference found in attitude and behavior change and Environment factor in substance dependence.

\begin{tabular}{|c|c|}
\hline Difference & $41.40 \%$ \\
\hline Chi Sqaured & 30.73 \\
\hline DF & 1 \\
\hline Significance & $\mathrm{P}<0.0001$ (Significant) \\
\hline $95 \% \mathrm{CI}$ & $26.52 \%$ to $54.29 \%$ \\
\hline
\end{tabular}

Table 8: Comparison of percentage proportions of substance dependence in the category of Goals Achieved and Vulnerability in Substance Dependence.

Above Table gives comparison of proportions of percentages of Goals Achieved in therapy vs Vulnerability factor in Substance dependence and the following were the results we used Comparison of proportions to compare percentages, if we see the difference we will find it is $41.4 \%$ stating there is a huge difference between Goals Achieved in therapy and Vulnerability factor and chi square comes out to be $30.73, \mathrm{p}<0.0001$, which is highly significant, this states that there is significant difference found in Goals achieved in therapy and Vulnerability factor in substance dependence.

\begin{tabular}{|c|c|}
\hline Difference & $29.70 \%$ \\
\hline Chi Sqaured & 16.12 \\
\hline DF & 1 \\
\hline Significance & $\mathrm{P}=0.0001$ (Significant) \\
\hline 95\%CI & $14.66 \%$ to $43.35 \%$ \\
\hline
\end{tabular}

Table 9: Comparison of percentage proportions of substance dependence in the category of Goals Achieved and Environment in Substance Dependence.

Above Table gives comparison of proportions of percentages of Goals Achieved in therapy vs Environment factor in Substance dependence and the following were the results we used Comparison of proportions to compare percentages, if we see the difference we will find it is $29.70 \%$ stating there is a huge difference between Goals Achieved in therapy and Environment factor and chi square comes out to be $16.12, \mathrm{p}=0.0001$, which is highly significant, this states that there is significant difference found in Goals achieved in therapy and Environment factor in substance dependence.

\section{Discussion}

\section{Study 1}

The purpose of this study was to assess the neuropsychological functioning of clients and to examine the relationship between neuropsychological functioning and treatment efficacy. It may be that understanding how deficits in neuropsychological functioning affect an individual's behaviors (e.g., relapse, missing treatment sessions, and dropping out of treatment) may help to change attitudes of clinicians and others who may currently negatively stigmatize those with substance use disorders (e.g., believing that the individual is lazy, unmotivated, etc.) [13].

In this study, participants were given a battery (COGNISTAT) for the assessment of neuropsychological status. The neuropsychological functioning of 100 adult males showed impaired functioning on measures; though not every individual was impaired on every measure; some were impaired on each measure. Thoughno selective attention impairments were detected among substance dependent patients but impairment can be seen in domain of Calculations and Judgment. Individuals using substance for long time have been found to have weaknesses with their working memory leading to 


\section{Psychology \& Psychological Research International Journal}

difficulty with problems involving the decision making and processing the information Studies in the past have been done in connection between working memory weakness and math difficulty, arithmetic, algorithm knowledge and problem solving in Substance dependent individuals as seen in the present study regarding the participants having deficits in judgment and mathematic. Impairment in cognitive functioning can also influence the individual and environmental factors which are involved in the treatment of substance dependence disorder. The impaired cognitive functioning results in poor decision making which can complicate the process of readiness to change and new behavior learning and therefore decreasing the self-efficacy of the individual. Patients with severe cognitive impairments are also less able to use their own resources during management.

\section{Study 2}

This section presents the results from content analysis as five super ordinate categories. Many of the names of the themes are taken from the words the informants used to describe their recovery in the therapeutic process:

As the therapy started the participants naturally started with how they ended up being addicted to substances. It became clear as the interviews progressed that it was common for the informants to have entered addiction with someone. Participants in the study mentioned various reasons for their dependence on substances. Their reasons include the following: experimentation, biological, depression, peer group pressure, availability and family. The results findings shows that there is no significant difference between Vulnerability factors and Environmental factors that contributed to getting into substance $(2.61, \mathrm{p}=0.1057)$ and both of these factors are responsible for getting into substance. Making a change in one's behavior and attitude toward their problem can be the greatest and hardest venture to treatment. Patients are not very hopeful and confident about one self to make a change in their lives. Also making a change is also dependent on various others factors like family environment of the patient, patient style of coping with stress, their ability to change in the process, maintain the change and adjusting with the normal functioning of their daily activities $[14,15]$.

According to the findings of the present study $51.3 \%$ of the total participants population experienced positive outcome from the therapy and there was significant difference between the positive and neutral response from the therapy $(\mathrm{p}=0.0072)$.The current findings also reflects that there is strong connection of optimism with treatment interventions. The participants higher in optimism find various ways to address problems in their lives due to substance use besides seeking formal treatment for the same.

In the present study it has been found that those stressful life situations create opportunities in life where behavior is influenced by self-efficacy. However, applying self-efficacy theory to behavior change in participants struggling with addiction is not an easy task it depends more on an individual. The participants were motivated for improving ones identity and thus it positively impacts treatment outcomes among those who desire to quit substance. Development of efficacy beliefs in each participants help them to understand the phases of personal change from whether to change the behavior at all, to whether he succeeds at initiating the change, to whether the change is successfully maintained. The participants realized that the process of recovery was something that would take time and effort on their part. Their life would not instantly transform into the life that they wanted. In order to have the opportunities they wanted, like a job or happy family life, they had to be persistent and stand in whatever adversity the recovery process would send their way.

The future was also something the participants discussed in addition to their present recovery situation. They compared themselves to other people and realized that drugs had hindered them in achieving the life they wanted. Being able to live a stable and independent life was something they envisioned achieving now that they were in recovery.

\section{Limitations}

1. The limitations of the study have to do firstly with the characteristics of the sample. The fact that the sample consisted of men from varying age groups, however the differences in experience and interpretations across the varying age groups was not explored .

2. A qualitative study focused on stress in recovery from drug addiction was only studied on males, but in relation to gender differences as it seems to affect women negatively, more so than men. This could contribute to more knowledge on the need for genderspecialized treatment

3. Increasing the number of participants by accessing multiple study sites could be another way to evaluate OAM based therapy with substance dependent patients in a more comprehensive manner 


\section{Psychology \& Psychological Research International Journal}

\section{Implications}

The results of the outcome of the therapy based on OAM can assist the therapist other mental health professional in making the therapeutic experience meaningful for both substance dependent patient and therapist. Future studies can examine the direct relationship between optimism and treatment seeking and also helps in making the therapy effective.

\section{Conclusion}

1. A subset of participants did demonstrate a significant increase in confidence over the course of treatment and were more focused on changing one's attitude and behavior.

2. During the interviews the participants were asked several times if they noticed any transformations in certain areas of social relations, personality or daily life.

3. The aim of these questions has been the exploration of differences between the personal condition before and after the substance - use assisted psychotherapy.

4. The participants realized that the process of recovery was something that would take time and effort on their part.

5. Their life would not instantly transform into the life that they wanted. In order to have the opportunities they wanted, like a job or happy family life, they had to be persistent and stand in whatever adversity the recovery process would send their way

\section{References}

1. Caldwell BM, Bradley RH [1978] Manual for the Home Observation for Measurement of the Environment. Little Rock AR: University of Arkansa Press.

2. Hawkins JD, Catalano RF, Miller JY (1992) Risk and protective factors for alcohol and other drug problems in adolescence and early adulthood: Implications for substance abuse prevention. Psychol Bull 112(1): 64-105.

3. Duka T, Townshend JM, Collier K, Stephens DN (2003) Impairment in cognitive functions after multiple detoxifications in alcoholic inpatients. Alcohol Clin Exp Res 27(10): 1563-1572.

4. Loeber S, Duka T, Welzel H, Nakovics H, Heinz A, et al. (2009b) Impairment of cognitive abilities and decision making after chronic use of alcohol: The impact of multiple detoxifications. Alcohol Alcohol 44(4): 372-381.

5. Ornstein TJ, Iddon JL, Baldacchino AM, Sahakian BJ, London $M$, et al. (2000) Profiles of cognitive dysfunction in chronic amphetamine and heroin abusers. Neuropsychopharmacology 23(2): 113-126.

6. Sullivan EV, Fama R, Rosenbloom MJ, Pfefferbaum A (2002) A profile of neuropsychological deficits in alcoholic women. Neuropsychology 16(1): 74-83.

7. Tapert SF, Brown SA (2000) Substance dependence, family history of alcohol dependence and neuropsychological functioning in adolescence. Addiction 95(7): 1043-1053.

8. BanerjeeP, Swati Yadav, Amita Puri (2016) Construction of a test on optimism index: Peroma Perspective. Journal of psychology and Clinical psychiatry 5(6): 00310.

9. Miller JD, Flory K, Lynam DR, Leukefeld C (2003) A test of the four-factor model of impulsivity-related traits. Personality and Individual Differences 34(8): 1403-1418.

10. Sobell LC, Sobell MB, Brown J, Cleland PA (1995) A randomized trial comparing group versus individual guided self-change treatment for alcohol and drug abusers. Poster presented at the 29th Annual Meeting of the Association for Advancement of Behavior Therapy, Washington, DC.

11. Caplan G, Killilea M (1976) Support Systems and Mutual Help. New York, Grune \& Stratton.

12. Scheier MF, Carver CS, Bridges MW (1994) Distinguishing optimism from neuroticism (and trait anxiety, self-mastery, and self-esteem): A reevaluation of the Life Orientation Test. J of Pers Soc Psychol 67(6): 1063-1078.

13. Ersche KD, Sahakian BJ (2007) The neuropsychology of amphetamine and opiate dependence: Implications for treatment. Neuro psychol Rev 17(3): 317-336.

14. Robinson L, Smith M, Saisan J (2014) Drug Abuse and Addiction.

15. Berg I, Dolan Y (2001) Tales of solutions: A collection of hope-inspiring stories. New York, NY: Norton. 